\title{
Effect of the Knee Replacement Surgery on Activity Level Based on Activpal: A Systematic Review and Meta-analysis Study
}

Huda Alfatafta ( $\square$ huda.alfatafta@etk.pte.hu )

University of Pécs

Mahmoud Alfatafta

University of Jordan

David Onchonga

University of Pécs

Sahar Hammoud

University of Pécs

Haitham Khatatbeh

University of Pécs

lu Zhang

University of Pécs

Imre Boncz

University of Pecs

Szimonetta Lohner

University of Pécs

Bálint Molics

University of Pecs

\section{Research Article}

Keywords: Knee replacement, ActivPAL, Activity level

Posted Date: January 31st, 2022

DOI: https://doi.org/10.21203/rs.3.rs-1261100/v1

License: (c) (i) This work is licensed under a Creative Commons Attribution 4.0 International License.

Read Full License 


\section{Abstract}

Background: The knee replacement (KR) surgery is done to restore the activity level and reduce the risk of experiencing disabilities. The outcomes of this surgery is evaluated mainly with subjective tools or low validity objective tools. However, the effect of the surgery on activity level using high validity objective accelerometer is still in question.

Methods: A systematic review and meta-analysis were conducted to find out if the knee replacement surgery alone could enhance the physical activity based on high validity accelerometer, ActivPAL, after at least six months of the surgery. Two independent reviewers evaluated five electronic databases (Cochrane-Central-Register-of-Controlled Trials, EMBASE, PubMed, and Web of Science, and Scopus) to find relative studies between January 2000 and October 2021. The quality assessments and risk of bias assessments were examined.

Results: Three articles were included with 202 participants (86 males, 116 females), with an average age of 64 years and an average $32 \mathrm{~kg} / \mathrm{m}^{2}$ body mass index. The results found that the number of steps was significantly improved up to $36.35 \%$ and $45.5 \%$ after six-months and one-year of the surgery, respectively. However, these changes did not meet the recommended activity level guideline and could be related to the patients' health status and their activity level before the surgery. No significant changes were seen in sedentary time, standing time, and upright time after six-months and one-year follow-up. Heterogeneity among studies was low to moderate ( $0 \%-57 \%)$.

Conclusion: The knee replacement surgery is an effective treatment to improve the quality of life in patients with severe knee injuries; however, to achieve the maximum benefit of the surgery the sedentary time should be reduced. Various factors have impacts on surgical success. Thus, further studies are needed to add these factors using high validity monitors.

\section{Background}

The knee replacement surgery is the final performance to deal with severe knee injuries such as advanced knee osteoarthritis $[1,2]$. The main outcomes of this surgery are reducing the pain and increasing the quality of life and the physical activity (PA) level of the patients [2]. The success of this surgery depends on the patients' satisfaction in terms of quality of life improvement after the surgery including the physical level $[2,3]$. Physical improvement is not only important to increase self-satisfaction but also to enhance musculoskeletal and cardio-respiratory functions, reduce the risk of falls, improve physical function, and reduce the risk of death [4].

Most of the available studies that evaluated the PA level after the surgery used subjective methods only such as questionnaires [5-7].The mainly used questionnaires that evaluate the quality of life and the PA level improvements are 36-item short-form health survey (SF-36), the Western Ontario and McMaster Universities Osteoarthritis Index (WOMAC), the Knee injury and Osteoarthritis Outcome Score(KOOS), and the Oxford Knee Score (OKS) [8]. However, those questionnaires are subjective evaluation methods that 
are associated with limited reliability and recall bias $[8,9]$. Therefore, the PA after the surgery remains doubtful, unclear, and evaluated with inaccuratemethods.

Several studies have relied on different types of objective monitors (accelerometer or pedometer); however, most of these monitors have low validity and reliability[10-12]. On the other hand, few studies have used high validity and reliability objective monitors to measure PA level among elderly population. To our knowledge, no systematic review and meta-analysis studies focused on evaluating the PA level after the surgery based on only high validity and reliability objective monitors such as ActivPAL (PAL Technologies, Glasgow, UK).

ActivPAL is a light-weight $(20 \mathrm{~g})$ subjective uniaxial accelerometer that is used widely to evaluate the PA level. This monitor detects the inclination of the thigh to determine body movement [13-16]. The ActivPAL is a valid and reliable device to measure the time spent in sedentary, standing, upright and stepping states and the number of steps per day. It is valid to evaluate children, adults, elderly, and slow walking population with less than $1 \%$ absolute misclassification error compared with observation $[14,15]$. Also, it has a high reliability (between $0.97-0.99$ ) $[14,15]$. Thus, this monitor is more recommended to be used than other monitors to evaluate the elderly populations [17]. For the previously mentioned criteria of the ActivPAL, this study is focusing on evaluating the studies that used the ActivPAL as a monitor for data collection.

The patients who decided to make the KR surgery are expecting to reach the outcomes of the surgery. However, the outcomes of the surgery are still doubtful as some patients feel that their activity level after the surgery did not change significantly, while only less than $5 \%$ of them had restored their activity level after 1-2 years of the surgery $[18,19]$. Besides, their activity level after the surgery still does not meet the recommended guidelines of the activity level of 150 minutes per week of moderate-intensity physical activities $[20,21]$. Thus, it is critical to identify the activity level enhancement after the knee replacement surgery using high validity monitor. To date, no systematic review is available to determine the PA level improvement using the ActivPAL. Hence, this study aims to understand the objective improvement after knee replacement to find out if the KR surgery can significantly enhance the quality of life or not, based on high-quality accelerometer.

\section{Methods}

This systematic review study is reported based on PRISMA (Preferred Reporting Items for Systematic Reviews and Meta-analysis) guidelines [22].

\subsection{Search strategy}

Five electronic databases including Cochrane Central Register of Controlled Trials, EMBASE, PubMed, and Web of Science, and Scopus were searched for relevant studies. Two independent reviewers conducted a research based on the search strategy. This strategy was adapted for the different databases as required (Appendix 1). The search was performed from January 2000 until the end of October 2021. 


\subsection{Study screening}

Two authors independently selected studies based on predefined inclusion criteria. The titles and abstracts were reviewed first, and irrelevant references were excluded. Then full-text publications of potentially relevant studies were obtained and checked for final inclusion. The references and related articles of the selected studies were screened for more suitable studies. Any disagreement was resolved by discussion among the two authors with the possibility to involve a third author as a consultant to make a final decision. Authors were contacted for more information or clarifications if needed it.

\subsection{Eligibility criteria}

All English language published studies that evaluated the PA level improvement before and after knee replacement surgery using the ActivPAL were included. No limits to the study designs. Besides, included articles must meet the following criteria:(a) adult participants who received knee replacement surgery, (b) minimum follow-up time is 6 months, and (c) the physical activity level is measured by the ActivPAL. The study was excluded if (a) it combined the knee replacement surgery with any other interventions, or (b) using another accelerometer.

\subsection{Data extraction and risk-of-bias assessment}

The two reviewers used the same extracted datasheet to report the following aspects: study information (author, year), study design, number of participants, patients 'demographic, preoperative activity level, postoperative activity level, main findings, and funding resources.

The reviewers evaluated the quality of reporting according to the Strengthening the Reporting of Observational Studies in Epidemiology tool (STROBE) for the non-randomized controlled studies which has 22 items to assess the reporting quality of title and abstract, introduction, methods, results, and discussion sections [23, 24]. Moreover, the Risk Of Bias In Non-randomized Studies (ROBINS-I) tool was used to evaluate the risk of bias in non-randomized controlled studies by evaluating seven dominates of bias (confounding, selection, measurement of interventions, missing data, measurement of outcomes, and reporting) [25]. For the non-randomized uncontrolled studies, the National Institutes of Health (NIH) quality assessment tool was used to evaluate the quality of pre-post studies without a control group [26].

\subsection{Statistical analysis}

The Cochrane Collaboration's Review Manager Program (RevMan version 5.3, Cochrane collaboration, Oxford, UK) used for data analysis. Weighted mean differences (WMDs) and corresponding 95\% confidence intervals (Cls) were estimated by Fixed-effect meta-analysis. The chi-square test for $\mathrm{Q}$ and the $1^{2}$ quantity were used to test heterogeneity between studies. Significant results were considered if a pvalue for chi-square test $\leq 0.1$ and $\mathrm{I}^{2} \geq 50 \%[22]$.

\section{Results}


A total of 12952 relevant studies was found initially. After removing duplicated articles and reviewing the title and the abstract, 420 articles remained. Then, four of them only met the inclusion criteria after the full text examination [20, 27-29] (Figure 1). Later, one of them was excluded because it was only a protocol study [27]. Finally, three studies only were included and two of them is uncontrolled studies.

\subsection{Systematic review}

The three included studies were prospective and only one of them includes a control group (Table 1 and 2). The total number of patients was 173 participants (more than $50 \%$ females) with an average age of 63.3 years and an average of $33.2 \mathrm{~kg} / \mathrm{m}^{2}$ body mass index (Table 1 ).

Granat et al., 2020 [20] evaluated 33 participants after six-months and one year of unilateral total knee replacement surgery. The patients used the ActivPAL for seven consecutive days at each stage. The monitor was attached over the mid-thigh. The results found that the stepping time and steps' number after six-months and one year of having the surgery significantly improved compared to pre-surgery. The number of steps improved significantly by $14.4 \%$ and $45.6 \%$ after six-month and one year, respectively. Moreover, the stepping time improved significantly by $11.48 \pm 2.05(19.38 \%) \mathrm{min} /$ day and by $22.66 \pm 2.24$ (38.77\%) $\mathrm{min} /$ day after six-months and one year, respectively. However, the changes in stepping time and the number of steps did not meet the PA guideline of 150 minutes of activity per week. While no significant differences were seen in sedentary time, standing time, and upright time.

Lützner et al.,2014 [28] assessed 97 patients after one year of unilateral total knee replacement surgery. The patients used the ActivPAL for four consecutive days. The monitor was attached over the anterolateral tibia. This study found that the number of steps increased from $5278 \pm 2999$ to $6473 \pm 3654$ steps/day (20.36\%) after one year of the surgery. However, no significant changes in sedentary, stepping, and standing times were demonstrated. Furthermore, only 16 participants met the PA guidelines.

Frimpong et al., 2020[29] examined 43 participants after six-months of unilateral total knee replacement surgery. The patients used the ActivPAL for seven consecutive days. The monitor was attached over midthigh. The results found that the number of steps was significantly improved (with an average of 2559 to 3515 steps/day, $P=0.001,37.35 \%$ ) and the walking time significantly increased (with an average 79 to 101 minutes/day, $P=0.006,27.2 \%$ ) after six-months of the surgery. Nevertheless, no significant changes in sedentary and sitting times were reported.

\subsection{Meta-analysis results}

The meta-analysis was used to evaluate the activity level enhancement after six months and one year and the results revealed that the heterogeneity of the activity level after six months and one year is low (table 3-5). After six months of the surgery, the number of steps ( 2 studies, 164 participants) improved $\left(95 \% \mathrm{Cl}-0.76,-0.14 ; \mathrm{P}=0.36 ; \mathrm{I}^{2}=0 \%\right)$ with low heterogeneity. Based on the same two studies, the sedentary time, stepping time, and standing time were improved but insignificantly (Table 3). After one year of the surgery, the number of steps (three studies, 153 participants) enhanced $(95 \% \mathrm{Cl}-2220,-791.82 ; \mathrm{P}=0.59$; 
$\mathrm{I}^{2}=0 \%$ ) with low heterogeneity (Table 3 ). The sedentary time, stepping time, standing time (two studies, 130 participants) were also insignificantly improved (Table 5). However, the overall heterogeneity after six months and one year was low and up to $\mathrm{I}^{2}=45 \%, \mathrm{P}=0.11$ (Tables $3-5$ ).

\subsection{Reporting quality and Risk of bias assessments}

The accepted articles were non-randomized studies; thus, the STROBE was used to assess the study's generalizability. In terms of title and abstract, the three accepted studies had a clear informative abstract. For the introduction, also all of the studies provide critical background with specified objectives. In term of methods and results, all the studies clearly described the study design, data collection, recruitment process, participants' criteria, the main measurable variables, and the main outcomes. For the discussion, all studies revealed the main key points, compared their findings with other studies, and stated the associated limitations. For funding, two studies reported their source of funding $[20,28]$.

ROBINS-I tool was used to evaluate the risk of bias in the controlled study, Lützner et al.,2014 [28] (Appendix 2). That study is associated with selection bias and performance bias. The researchers attached the ActivPAL on the tibia which is not a recommended location; besides, it collected the data of four days which is not very enough to evaluate the AP.

\section{Discussion}

The knee replacement is not an easy decision-making intervention to cope with severe knee injuries. The patients expect that the KR surgery will help them to restore their physical activity, be more active, and to be more independent. Hence, a systematic review study was conducted to evaluate the PA improvement after the surgery using the ActivPAL. This study focused on the PA that was examined with the ActivPAL as it is a very accurate monitor, suitable to evaluate the sedentary time of the elderly population, and more recommended to be used than the ActiGraph[17]. The main finding of this study is only the number of steps was significantly improved after the surgery among most of the patients[20, 27-29].

Nevertheless, this improvement still not enough to restore their normal activity level as it did not reach to recommended activity level guideline. Moreover, the sedentary time did not reduce significantly after the surgery which could reduce the effectiveness of the KR surgery.

It is expected that the outcomes of the included studies are associated with participants' health status before the surgery. For instance, the average age of the included participants in Granat et al., 2020 study[20] was considerably low (59 \pm 6 years old, range: 49-76 years old). In Lützner et al.,2014 study [28], the participants had a high number of steps (with an average of 5000 steps/day) before the surgery. Similarly, Frimpong et al., 2020 study [29] found significant differences in the number of steps after six months and that could be related to include patients with body mass index less than $30 \mathrm{~kg} / \mathrm{m}^{2}$. Therefore, the age, body mass index, and activity level of the patients before the surgery could be correlated with the outcomes of the KR surgery. 
Other factors also could has impacts on the outcomes of the KR surgery. It has been suggested that the KR surgery could increase the movement-related activity and number of sit-to-stand movements by $0.7 \%$ and $9.7 \%$ respectively after six-months and that depends on body mass of the patients and the physical treatment after the surgery [31]. Another study found that the male and young age ( $<65$ years old) patients show better PA levels after the surgery than women and elderly participants [32]. Furthermore, the emotional state of the patients and their partners has an influence on the PA recovery after the surgery [33]. Therefore, more researches are required to understand the impact of these factors and find other factors.

Our results match with other studies which evaluated the PA level after at least six-months of having the KR surgery using other types of activity monitors. These studies also found small changes in the AP after six-months of the surgery as patients still inactive and have high sedentary time after the surgery[31-35]. Similarly, the available systematic review studies, that reported the PA after the KR surgery using other types of activity monitors, found that the changes in the AP after six-month of the surgery, and only moderate changes could be seen in the PA after one year of the surgery but still not insufficient [10-12].

To sum up, even the subjective measures such as pain, function, and stiffness were improved, not all aspect of the activity level based on the objective tools were significantly improved after the KR surgery. So far, no enough evidence about the benefit of this surgery on the PA level are available. Hence, better physical capability after the surgery does not mean a better PA level.

\subsection{The limitations}

This study is engaged with limitations. Few studies met the inclusion criteria and none of them is a randomized controlled study; therefore, the results of the included studies could be associated with a high risk of bias such as selection bias and performance bias. Also, this study included only studies that used the ActivPAL and excluded studies with any other interventions with the surgery which limit the results' generalizability.

\section{Conclusions}

The total knee replacement surgery is an effective treatment to improve the quality of life among patients with severe knee injuries. Based on high validity monitor, the number of steps improved significantly, but the sedentary time did not changed. To increase the maximum benefits of the surgery, the sedentary time should be decreased. Hence, long-term follow-ups, rehabilitation programs, and physical interventions are important to enhance the physical outcomes after the surgery. This finding could be important for specialists who work with the KR patients to restore their activity level after the surgery and make them more satisfied. The patients' expectations after the surgery should be discussed with the patients before the surgery.

\section{Abbreviations}


KR: The knee replacement

PA: Physical activity

SF-36: 36-item Short-form

WOMAC: Western Ontario and McMaster Universities Osteoarthritis Index

KOOS: Knee injury and Osteoarthritis Outcome Score

OKS: Oxford Knee Score

STROBE : Strengthening the Reporting of Observational Studies in Epidemiology tool

ROBINS-I : Risk Of Bias In Non-randomized Studies

$\mathrm{NIH}$ : National Institutes of Health

WMDs : Weighted mean differences

Cls : Confidence intervals

\section{Declarations}

Ethics approval and consent to participate: not applicable.

Consent for publication: not applicable.

Acknowledgements: not applicable.

Availability of data and materials: The datasets generated and/or analyzed during the current study are not publicly available because the dataset is very large but are available from the corresponding author on reasonable request.

Competing interests: None. The authors declare that they have no competing interests (financial and nonfinancial).

Funding: no

Authors' contributions: With the submission of this manuscript I would like to confirm that the first authors, Huda Alfatafta and Mahmoud Alfatafta, are sharing the first authorship. Also, all authors of this paper, David Onchonga, Sahar hammoud, Haitham Khatatbeh, lu Zhang, Imre Boncz, Szimonetta Lohner and Baliant Molics, have directly participated in the planning, execution, and analysis of this study. All authors of this paper have read and approved the final version submitted, and they have no conflict of interest. 


\section{References}

1. Tambascia RA, Vasconcelos RA, Mello W, Teixeira PP, Grossi DB. Pre-operative Functional Parameters of Patients Undergoing Total Knee Arthroplasty. Physiother Res Int 2016; 21(2):77-83. http://dx.doi.org/10.1002/pri.1622.

2. Lingard EA, Sledge CB, Learmonth ID, Group KO. Patient expectations regarding total knee arthroplasty: differences among the United States, United Kingdom, and Australia. JBJS 2006; 88(6):1201-7. doi: 10.2106/JBJS.E.00147.

3. Ferket BS, Feldman Z, Zhou J, Oei EH, Bierma-Zeinstra SM, Mazumdar M. Impact of total knee replacement practice: cost effectiveness analysis of data from the Osteoarthritis Initiative. bmj 2017; 356. https://doi.org/10.1136/bmj.j1131.

4. Hoorntje A, Witjes S, Kuijer PPF, Bussmann JB, Horemans HL, Kerkhoffs GM, et al. Does activitybased rehabilitation with goal attainment scaling increase physical activity among younger knee arthroplasty patients? Results from the randomized controlled ACTION trial. The Journal of arthroplasty 2020; 35(3):706-11.https://doi.org/10.1016/j.arth.2019.10.028.

5. Nutton RW, van der Linden ML, Rowe PJ, Gaston P, Wade FA. A prospective randomised double-blind study of functional outcome and range of flexion following total knee replacement with the NexGen standard and high flexion components. J Bone Joint Surg Br 2008; 90(1):37-42. http://dx.doi.org/10.1302/0301-620X.90B1.19702.

6. Nutton RW, Wade FA, Coutts FJ, van der Linden ML. Does a mobile-bearing, high-flexion design increase knee flexion after total knee replacement? J Bone Joint Surg Br 2012; 94(8):1051-7. http://dx.doi.org/10.1302/0301-620X.94B8.28828.

7. Nutton RW, Wade FA, Coutts FJ, van der Linden ML. Short term recovery of function following total knee arthroplasty: a randomised study of the medial parapatellar and midvastus approaches. Arthritis 2014; 173857.https://doi.org/10.1155/2014/173857.

8. Collins NJ, Roos EM. Patient-reported outcomes for total hip and knee arthroplasty: commonly used instruments and attributes of a "good" measure. Clinics in geriatric medicine 2012; 28(3):36794.https://doi.org/10.1016/j.cger.2012.05.007.

9. Collins NJ, Prinsen CA, Christensen R, Bartels EM, Terwee CB, Roos EM. Knee Injury and Osteoarthritis Outcome Score (KOOS): systematic review and meta-analysis of measurement properties. Osteoarthritis Cartilage 2016; 24(8):1317-29. http://dx.doi.org/10.1016/j.joca.2016.03.010.

10. Arnold JB, Walters JL, Ferrar KE. Does physical activity increase after total hip or knee arthroplasty for osteoarthritis? A systematic review. journal of orthopaedic \& sports physical therapy 2016; 46(6):431-42.https://www.jospt.org/doi/10.2519/jospt.2016.6449.

11. Almeida GJ, Khoja SS, Piva SR. Physical activity after total joint arthroplasty: a narrative review. Open access journal of sports medicine 2018; 9:55. https://doi.org/10.2147/OAJSM.S124439.

12. Hammett $T$, Simonian $A$, Austin $M$, Butler R, Allen KD, Ledbetter $L$, et al. Changes in physical activity after total hip or knee arthroplasty: a systematic review and meta-analysis of six and twelve month 
outcomes. Arthritis care \& research 2018; 70(6):892-901. https://doi.org/10.1002/acr.23415.

13. Edwardson CL, Winkler EA, Bodicoat DH, Yates T, Davies MJ, Dunstan DW, et al. Considerations when using the activPAL monitor in field-based research with adult populations. Journal of sport and health science 2017; 6(2):162-78.https://doi.org/10.1016/j.jshs.2016.02.002.

14. Grant PM, Dall PM, Mitchell SL, Granat MH. Activity-monitor accuracy in measuring step number and cadence in community-dwelling older adults. Journal of aging and physical activity 2008; 16(2):201-14. https://doi.org/10.1123/japa.16.2.201.

15. Grant PM, Ryan CG, Tigbe WW, Granat MH. The validation of a novel activity monitor in the measurement of posture and motion during everyday activities. British journal of sports medicine 2006; 40(12):992-7. https://doi.org/10.1136/bjsm.2006.030262.

16. Yang C-C, Hsu Y-L. A review of accelerometry-based wearable motion detectors for physical activity monitoring. Sensors 2010; 10(8):7772-88. https://doi.org/10.3390/s100807772.

17. Kim Y, Barry VW, Kang M. Validation of the ActiGraph GT3X and activPAL ccelerometers for the assessment of sedentary behavior. Measurement in Physical Education and Exercise Science 2015; 19(3):125-37.https://doi.org/10.1080/1091367X.2015.1054390.

18. Arnold JB, Walters JL, Solomon LB, Thewlis D. Does the method of component fixation influence clinical outcomes after total knee replacement? A systematic literature review. J Arthroplasty 2013; 28(5):740-6. http://dx.doi.org/10.1016/j.arth.2012.09.021.

19. Kahn TL, Schwarzkopf R. Does total knee arthroplasty affect physical activity levels? Data from the osteoarthritis initiative. The Journal of arthroplasty 2015; 30(9):15215.https://doi.org/10.1016/j.arth.2015.03.016.

20. Granat M, Williams A, Johnson DS, Jones R. Does free-living physical activity improve one-year following total knee arthroplasty in patients with osteoarthritis: a prospective study. Osteoarthritis and Cartilage Open 2020; 2(3):100065.https://doi.org/10.1016/j.ocarto.2020.100065.

21. Haskell WL, Lee I-M, Pate RR, Powell KE, Blair SN, Franklin BA, et al. Physical activity and public health: updated recommendation for adults from the American College of Sports Medicine and the American Heart Association. Circulation 2007; 116(9):1081. DOI: 10.1249/mss.0b013e3180616b27.

22. Page MJ, McKenzie JE, Bossuyt PM, Boutron I, Hoffmann TC, Mulrow CD, et al. The PRISMA 2020 statement: an updated guideline for reporting systematic reviews. Bmj 2021; 372. https://doi.org/10.1136/bmj.n71.

23. Vandenbroucke JP, von Elm E, Altman DG, Gotzsche PC, Mulrow CD, Pocock SJ, et al. Strengthening the Reporting of Observational Studies in Epidemiology (STROBE): explanation and elaboration. Int J Surg 2014; 12(12):1500-24. http://dx.doi.org/10.1016/j.ijsu.2014.07.014.

24. Vandenbroucke JP, von Elm E, Altman DG, Gotzsche PC, Mulrow CD, Pocock SJ, et al. Strengthening the Reporting of Observational Studies in Epidemiology (STROBE): explanation and elaboration. Ann Intern Med 2007; 147(8):W163-94. http://dx.doi.org/10.7326/0003-4819-147-8-200710160-00010w1. 
25. Sterne JA, Hernán MA, Reeves BC, Savović J, Berkman ND, Viswanathan M, et al. ROBINS-l: a tool for assessing risk of bias in non-randomised studies of interventions. bmj 2016; 355. https://doi.org/10.1136/bmj.i4919.

26. National Heart L, Institute B. Study Quality Assessment Tools: for Observational Cohort and CrossSectional Studies, for Before-After (Pre-Post) Studies With No Control Group, for Case-Control Studies. Maryland, USA Im Internet (Stand: 1001 2019): www nhlbi nih gov/health-topics/studyquality-assessment-tools.

27. Pellegrini CA, Lee J, DeVivo KE, Harpine CE, Del Gaizo DJ, Wilcox S. Reducing sedentary time using an innovative mHealth intervention among patients with total knee replacement: Rationale and study protocol. Contemporary Clinical Trials Communications 2021:100810.https://doi.org/10.1016/j.conctc.2021.100810.

28. Lützner C, Kirschner S, Lützner J. Patient activity after TKA depends on patient-specific parameters. Clinical Orthopaedics and Related Research 2014; 472(12):3933-40. https://doi.org/10.1007/s11999-014-3813-5.

29. Frimpong E, van der Jagt DR, Mokete L, Pietrzak J, Kaoje YS, Smith A, et al. Improvements in objectively measured activity behaviors do not correlate with improvements in patient-reported outcome measures following total knee arthroplasty. The Journal of arthroplasty 2020; 35(3):712-9. e4.https://doi.org/10.1016/j.arth.2019.10.016.

30. Cuijpers P, Weitz E, Cristea I, Twisk J. Pre-post effect sizes should be avoided in meta-analyses. Epidemiology and psychiatric sciences 2017; 26(4):364-8. https://doi.org/10.1017/S2045796016000809.

31. de Groot IB, Bussmann HJ, Stam HJ, Verhaar JA. Small increase of actual physical activity 6 months after total hip or knee arthroplasty. Clinical orthopaedics and related research 2008; 466(9):2201. https://doi.org/10.1007/s11999-008-0315-3.

32. Kersten RF, Stevens M, van Raay JJ, Bulstra SK, van den Akker-Scheek I. Habitual physical activity after total knee replacement. Phys Ther 2012; 92(9):1109-16. http://dx.doi.org/10.2522/ptj.20110273.

33. Kalisch T, Horst F, Gosheger G, Theil C, Seeber L, Moellenbeck B. Everyday Physical Activity and Sedentary Behavior After Total Joint Arthroplasty: Do Patients and Partners Develop an Active Lifestyle? Clinical Interventions in Aging 2021; 16:403. https://doi.org/ 10.2147/CIA.S295160.

34. Harding P, Holland AE, Delany C, Hinman RS. Do activity levels increase after total hip and knee arthroplasty? Clinical Orthopaedics and Related Research 2014; 472(5):1502-11. https://doi.org/10.1007/s11999-013-3427-3.

35. Moellenbeck B, Horst F, Gosheger G, Theil C, Seeber L, Kalisch T. Does total hip or knee arthroplasty have an effect on the patients' functional or behavioral outcome and health-related quality of life of the affected partners? The Journal of arthroplasty 2021; 36(3):88591.https://doi.org/10.1016/j.arth.2020.08.066. 


\section{Tables}

Table 1: Summary of the included studies. M: male. F: female.

\begin{tabular}{|llllll|}
\hline Authors & Type of study & Follow up & $\begin{array}{l}\text { Number of } \\
\text { participants } \\
\text { (M/F) }\end{array}$ & $\begin{array}{l}\text { Average } \\
\text { age } \\
\text { (years) }\end{array}$ & $\begin{array}{l}\text { Average } \\
\text { BMI(kg/m²) }\end{array}$ \\
\hline $\begin{array}{l}\text { Granat et } \\
\text { al., 2020 }\end{array}$ & $\begin{array}{l}\text { Uncontrolled } \\
\text { before-after } \\
\text { study }\end{array}$ & $\begin{array}{l}6 \text { months and } \\
12 \text { months }\end{array}$ & $33(6 \mathrm{~m}, 27 \mathrm{f})$ & $59 \pm 6$ & $\begin{array}{l}37.21 \pm 7.65 \\
\text { for females, }\end{array}$ \\
\hline $\begin{array}{l}\text { Lützner et } \\
\text { al., 2014 }\end{array}$ & $\begin{array}{l}\text { Controlled before- } \\
\text { after study }\end{array}$ & 12 months & $97(52 \mathrm{~m}, 45 \mathrm{f})$ & 68.9 & $\begin{array}{l}32.38 \pm 2.01 \\
\text { for males }\end{array}$ \\
\hline $\begin{array}{l}\text { Frimpong } \\
\text { et al., 2020 }\end{array}$ & $\begin{array}{l}\text { Uncontrolled } \\
\text { before-after study }\end{array}$ & 6 months & $43(\mathrm{NA})$ & $62.8 \pm 8.6$ & $32.3(30.3-$ \\
\hline
\end{tabular}

Table 2: Summary of results of the included studies. The highlighted results are with significant changes. (NA = not available) 


\begin{tabular}{|c|c|c|c|}
\hline Variables & Granat et al., 2020 & Lützner et al., 2014 & Frimpong et al., 2020 \\
\hline \multicolumn{4}{|l|}{ Before the surgery } \\
\hline Sedentary time (hour/day) & 19.48 & 12.2 & 22.7 \\
\hline Standing time(hour/day) & 3.47 & 10.8 & 13.25 \\
\hline Upright time(hour/day) & 4.48 & NA & NA \\
\hline Stepping time(hour/day) & $0.98^{*}$ & 1.4 & $3.3^{\star}$ \\
\hline Steps (number/day) & $4240 *$ & $5278 *$ & $2559 *$ \\
\hline \multicolumn{4}{|l|}{ After 6 months of the surgery } \\
\hline Sedentary time (hour/day) & 19.27 & NA & 11.8 \\
\hline Standing time(hour/day) & 3.64 & NA & 13.3 \\
\hline Upright time(hour/day) & 4.73 & NA & NA \\
\hline Stepping time(hour/day) & $1.17 *$ & NA & $4.2^{\star}$ \\
\hline Steps (number/day) & $4853^{\star}$ & NA & $3515^{\star}$ \\
\hline \multicolumn{4}{|c|}{ After 12 months of the surgery } \\
\hline Sedentary time (hour/day) & 19.08 & 12.2 & NA \\
\hline Standing time(hour/day) & 3.54 & 10.3 & NA \\
\hline Upright time(hour/day) & 4.88 & NA & NA \\
\hline Stepping time(hour/day) & $1.36^{\star}$ & 1.5 & NA \\
\hline Steps (number/day) & $6174^{*}$ & $6473^{\star}$ & NA \\
\hline
\end{tabular}


Table 3: Meta-analysis of steps (average number/day) after six months and one year of the surgery.

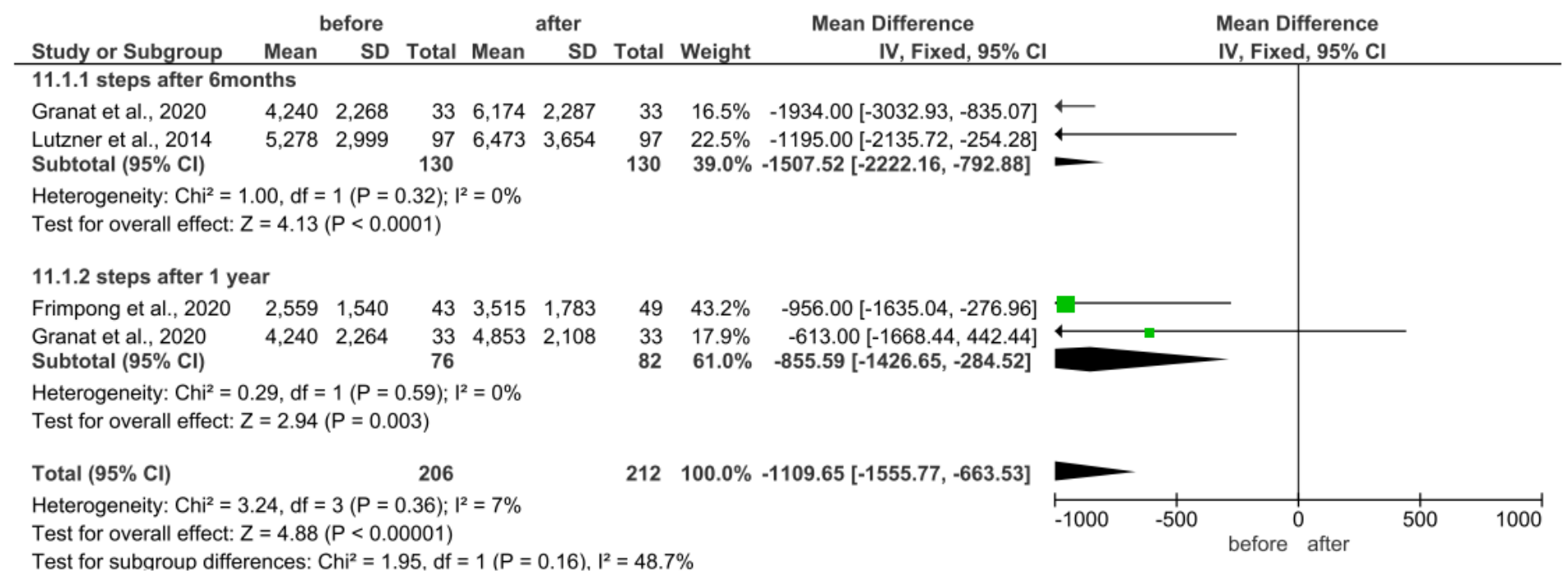

Table 4: Meta-analysis results (min/day) after six months of the surgery.

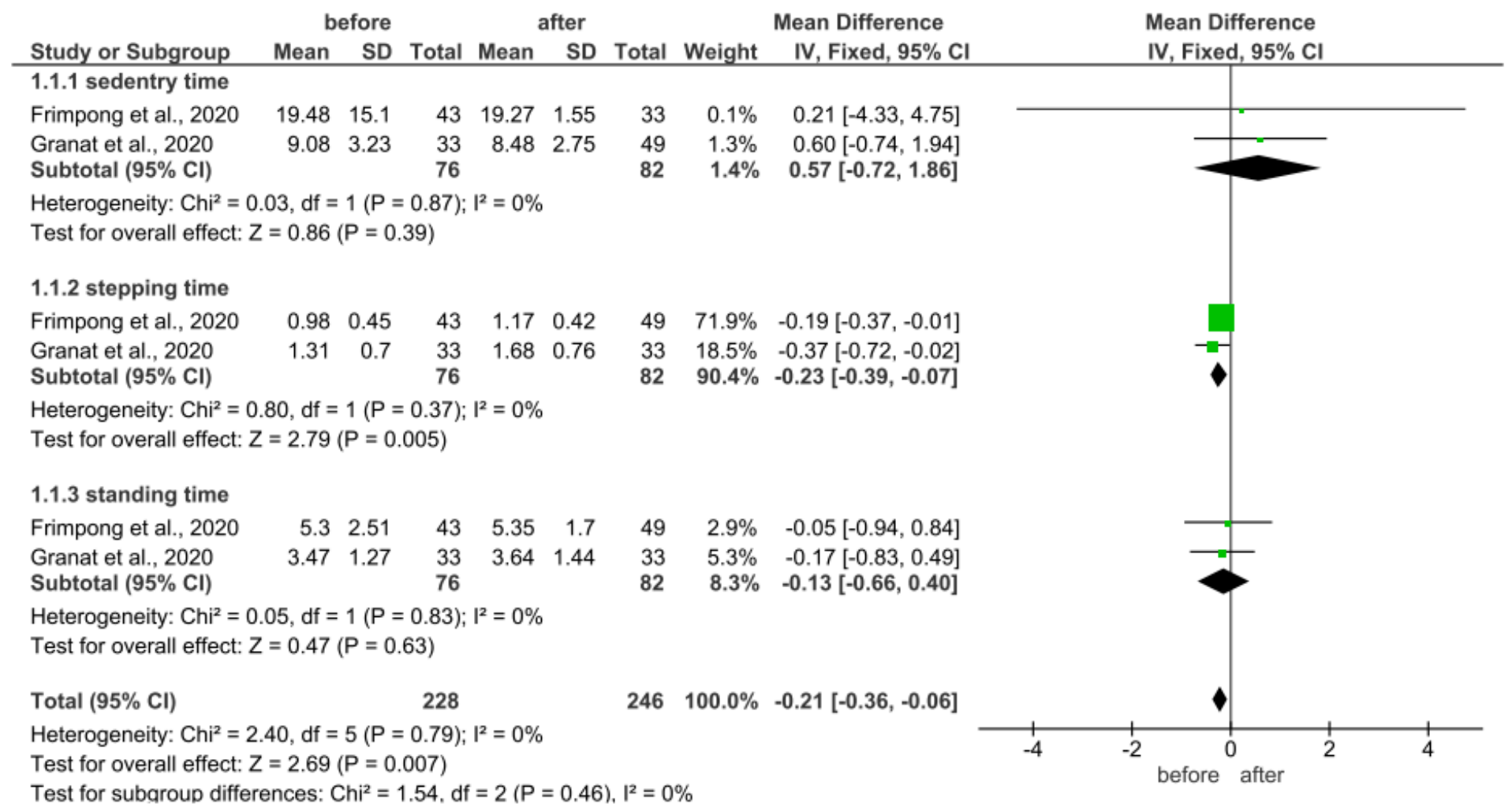

Table 5: Meta-analysis of the results ( $\mathrm{min} /$ day) after one year of the surgery. 


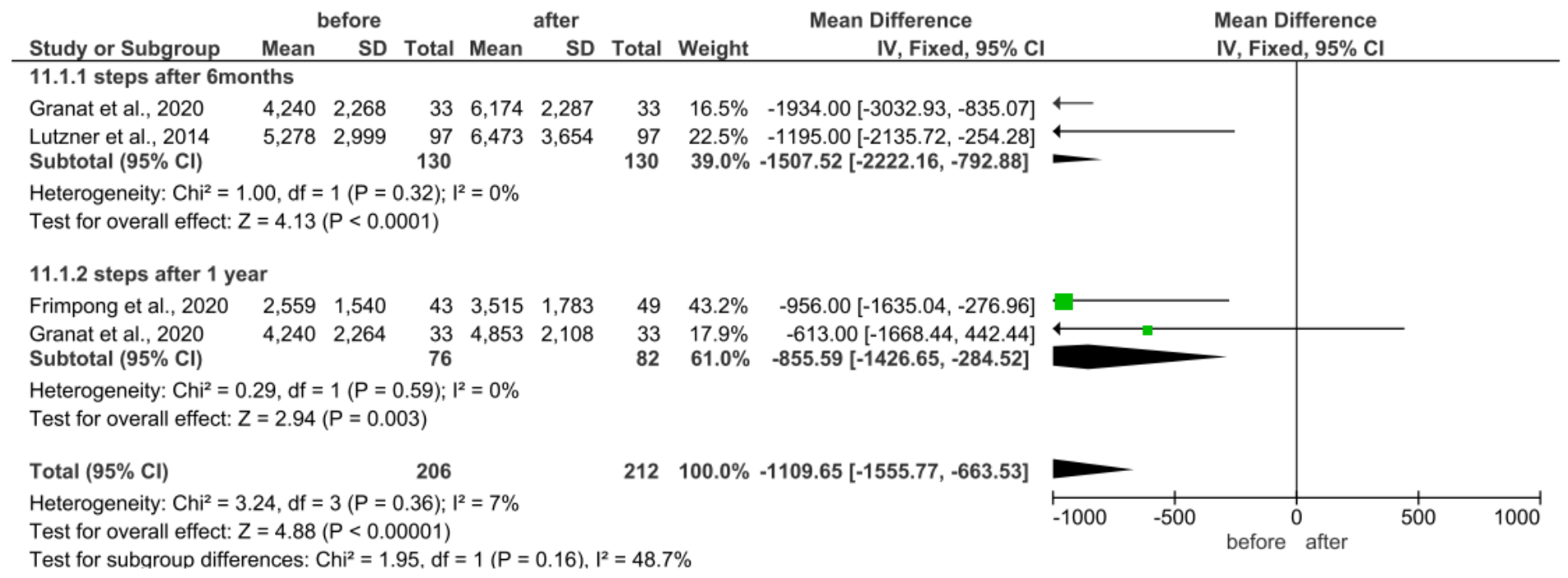

\section{Figures}
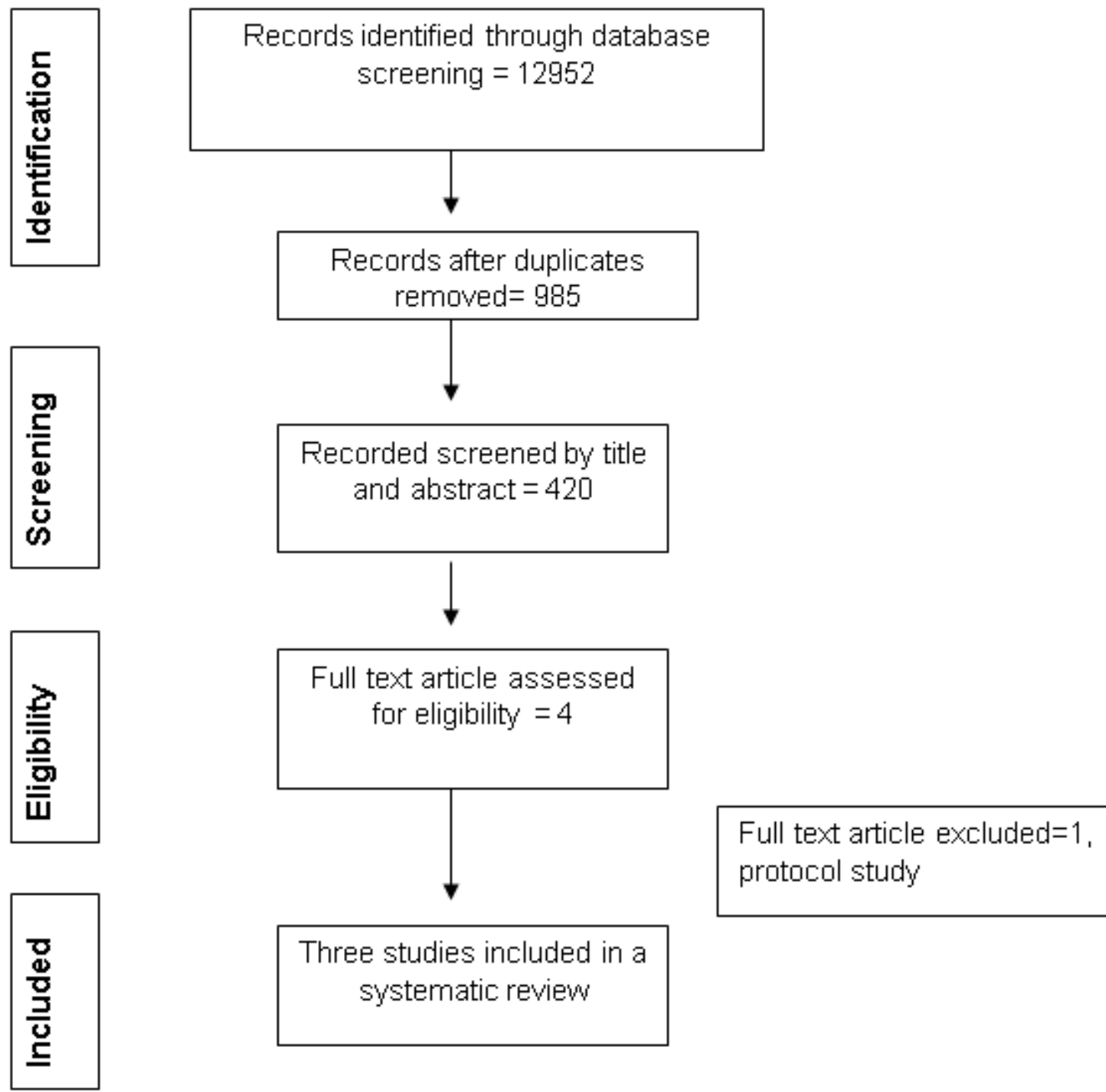

Three studies included in a systematic review 
Figure 1

PRIMSA flow chart of the study identification.

\section{Supplementary Files}

This is a list of supplementary files associated with this preprint. Click to download.

- Appendix.docx 